\title{
KEEFEKTIFAN PEMBELAJARAN IPA DENGAN MENGGUNAKAN MODUL AUDIO INTERAKTIF MENGENAL BAGIAN AKAR DAN FUNGSINYA UNTUK SISWA TUNANETRA KELAS IV DI SLB YPAB SURABAYA
}

\author{
Lutfi Isni Badiah, S. Pd., M.Pd \\ Dosen Prodi Bimbingan dan Konseling UNIPA Surabaya \\ Email: lutfiisnibadiah@gmail.com
}

\begin{abstract}
Abstrak
Penelitian ini bertujuan untuk mendeskripsikan keefektifan pembelajaran IPA dengan menggunakan modul interaktif mengenal bagian akar dan fungsinya untuk siswa tunanetra kelas IV di SLB YPAB Surabaya. Pendekatan yang digunakan peneliti adalah penelitian kuantitatif dengan metode eksperimen. Penelitian diadakan di SLB-A YPAB Surabaya. Subjek penelitian ini adalah siswa tunanetra kelas IV SLB-A YPAB Surabaya yang berjumlah 5 orang. Penelitian ini menggunakan sampling penuh dan menggunakan model desain treatment by subject design (one group Pre test-post test design), sedangkan pengumpul data menggunakan instrumen tes. Hasil dari penelitian ini diperoleh hasil uji hipotesis perhitungan nilai pretest dan posttest mengenai pembelajaran IPA menggunakan modul audio interaktif mengenal akar dan fungsinya dihasilkan nilai $Z$ hitung = 2.023 dengan $P=0.043$ dengan taraf signifikansi $(\alpha)$ 5\%. Sehingga dapat disimpulkan bahwa penggunaan modul audio interaktif mengenal akar dan fungsinya berpengaruh positif terhadap pembelajaran IPA pada siswa tunanetra kelas IV di SLB A YPAB Surabaya.
\end{abstract}

Kata kunci : siswa tunanetra, modul audio interaktif, pembelajaran IPA

\section{Pendahuluan}

Siswa tunanetra adalah individu yang mengalami gangguan penglihatan, sehingga mengalami keterbatasan dan kesulitan melakukan kegiatan sehari-hari termasuk kegiatan belajar. Dalam menyerap informasi/pesan, siswa tunanetra mengandalkan indera yang masih berfungsi dengan baik, diantaranya indera peraba (taktil) dan indera mendengar (keterampilan mendengar). Keterampilan mendengar yang diperoleh siswa tunanetra tidak didapat secara alami, namun harus diajarkan secara sistematis.

Keterampilan mendengar mempunyai peran penting dalam proses pembelajaran. 
Berbeda dengan siswa awas, hampir $80 \%$ informasi diperoleh dari indera visual, namun bagi siswa tunanetra, indera pendengarnya (auditory) menjadi salah satu sumber penting untuk memperoleh informasi sebagai kompensasi gangguan penglihatannya (Sunanto, 2005:78). Hal ini sejalan dengan pendapat Willis (1979), yang mengemukakan bahwa tunanetra menggunakan pendengaran sebagai media dua kali lipat dibandingkan dengan membaca. Sehingga pengembangan keterampilan mendengar bagi siswa tunanetra sangat diperlukan guna menunjang pembelajaran.

Ilmu Pengatahuan Alam (IPA) merupakan salah satu mata pelajaran yang mempelajari mengenai alam semesta dan berbagai mekanisme yang terjadi di dalamnya. Mata pelajaran ini berhubungan sangat erat dengan kehidupan sehari-hari, karena membahas mengenai kehidupan makhluk hidup, makanan, listrik, angin, air, dan tumbuhan. Namun banyak siswa yang keliru memahami bahwa IPA merupakan ilmu yang sulit, banyak istilah dan membuat pusing kepala. Seperti contoh pada materi mengenal bagian tubuh dan fungsinya khususnya akar tumbuhan. Materi ini membutuhkan banyak penjelasan dan pengarahan dari guru. Hal ini tentu akan membuat guru membutuhkan waktu lebih lama serta tenaga ekstra untuk menjelaskan pada anak tunanetra.

Media pembelajaran berbasis teknologi informatika juga banyak dihasilkan untuk menunjang pembelajaran siswa tunanetra, salah satunya adalah modul audio. Media ini mengandung pesan dalam bentuk auditif (hanya dapat didengar) sehingga dapat merangsang pikiran, perasaan, perhatian, dan membantu dalam memperoleh pengetahuan, keterampilan, atau sikap.

Keunggulan modul audio dalam kegiatan pembelajaran pada umumnya untuk melatih keterampilan yang berhubungan dengan aspek-aspek keterampilan mendengarkan (Hayati, 2012). Pembelajaran dengan modul audio interaktif sebagai media bagi siswa tunanetra untuk melakukan interaksi dengan pembelajaran. Penggunaan modul audio interaktif mengenal bagian akar dan fungsinya diharapkan dapat membantu mengoptimalkan organ pendenganran siswa tunanetra dan menstransfer informasi pada mata pelajaran IPA.

Dari uraian latar belakang di atas, peneliti tertarik untuk meneliti tentang keefektifan pembelajaran IPA dengan menggunakan modul audio interaktif 
mengenal bagian akar dan fungsinya untuk siswa tunanetra kelas IV di SLB YPAB Surabaya sebagai penunjang pembelajaran ilmu pengetahuan alam untuk membantu mengoptimalkan pendengaran siswa tunanetra dan memotivasi belajarnya.

Berdasarkan uraian latar belakang di atas, peneliti menguraikan rumusan pertanyaan penelitian adalah, "Bagaimana keefektifan Pembelajaran IPA dengan Menggunakan Modul Audio Interaktif Mengenal Bagian Akar dan Fungsinya untuk Siswa Tunanetra Kelas IV di SLB YPAB surabaya?". Sedangkan hipotesis dari penelitian ini adalah pembelajaran IPA menggunakan modul audio interaktif mengenal bagian akar dan fungsinya efektif untuk siswa tunanetra kelas IV Di SLB YPAB Surabaya.

\section{Metode Penelitian}

Penelitian diadakan di SLB-A YPAB Surabaya di Jalan Tegalsari No 56 Surabaya, dengan subjek penelitian ini adalah siswa tunanetra kelas IV SLB-A YPAB Surabaya yang berjumlah 5 orang. Dalam penelitian ini metode pengumpulan data dilakukan dengan instrumen tes. Tes yang digunakan adalah tes tertulis dengan bentuk tes obyektif (obyektive test). Pemberian tes ini berpedoman pada instrumen yang dibuat sesuai dengan tujuan dalam pembelajaran IPA yang merujuk pada kurikulum 2013 sekolah reguler kelas IV semester I. Kisi-kisi soal tes yang akan digunakan mengacu pada kurikulum 2013 sekolah reguler kelas IV semester I dengan kompetensi dasar 3.1. Menjelaskan bentuk luar tubuh hewan dan tumbuhan dan fungsinya. Untuk mengetahui kevalidan instrumen, penelitian ini menggunakan korelasi point biserial (rpbis). Sedangkan untuk pengujian reliabilitas dalam penelitian ini, digunakan rumus Cronbach's Alpha dengan bantuan program SPSS. Desain/rancangan penelitian ini menggunakan metode penelitian eksperimen. Teknik analisis data yang digunakan adalah teknik non-parametrik yaitu tes rangking bertanda Wilcoxon (Wilcoxon Sign Rank Test) dengan menggunakan Desain One Group Pre-Test Posttest Design.

Subjek penelitian ini adalah siswa tunanetra kelas IV SLB-A YPAB Surabaya yang berjumlah 5 orang. Penelitian ini menggunakan sampling penuh atau karena semua siswa dijadikan subjek penelitian. Instrumen penelitian disusun berdasarkan kisi-kisi instrumen penelitian tentang akar tumbuhan dan fungsinya yang sudah dikembangkan. Selanjutnya instrumen tes diuji cobakan guna mengetahui validitas 
dan reliabilitas instrumen tes. Uji coba dan analisis validitas dan reliabilitas instrumen tes dilaksanakan pada tanggal 22 November 2015. Try out diberikan kepada 25 siswa yang memiliki karakteristik kognitif yang sama dengan subjek penelitian, yaitu siswa kelas IV Sekolah Dasar. Instrumen yang digunakan dalam penelitian ini adalah berupa Tes, yaitu tes menjawab soal tertulis. Dari hasil uji validitas, didapat 11 soal yang valid, dan 14 soal gugur. Uji reliabilitas intrumen, menggunakan rumus Cronbach's Alpha dengan menggunakan program SPSS versi 20. Dari hasil perhitungan, didapat hasil reliabilitas adalah 0,68. Berdasarkan nilai koefisien reliabilitas tersebut dapat dikatakan bahwa soal tes memiliki reliabilitas yang cukup tinggi, sehingga maka dapat simpulkan bahwa soal tes tersebut sudah layak untuk digunakan sebagai instrumen penelitian. Lokasi penelitian bertempat di SLB A YPAB Surabaya dengan subjek penelitian sebanyak 5 siswa. Dibawah ini data dari subyek penelitian yaitu:

Tabel 5.1. Data siswa tunanetra kelas VI SLB A YPAB Surabaya.

\begin{tabular}{|c|c|c|}
\hline No. & Nama Siswa & Jenis Kelamin \\
\hline 1. & DN & L \\
\hline 2. & FD & L \\
\hline 3. & UM & L \\
\hline 4. & RK & L \\
\hline 5. & RD & L \\
\hline
\end{tabular}

Sumber data : Data Primer (2016)
Prosedur penelitian yang dilakukan yaitu dengan memberikan tes awal (pretest) kepada siswa untuk mengetahui kemampuan awal siswa sebelum diberikan treatment, kemudian setelah pemberian treatment siswa diberikan tes akhir (posttest) untuk mengetahui kemampuan hasil akhir siswa setelah dilakukan treatment. Hasil pretest dan posttest tersebut dijadikan dasar untuk mengetahui pemahaman siswa setelah diadakan treatment.

Analisis data yang digunakan untuk mengetahui keefektifan pembelajaran IPA dengan menggunakan modul interaktif mengenal bagian akar dan fungsinya untuk siswa tunanetra kelas IV di SLB YPAB Surabaya, dengan menggunakan statistik non parametrik dengan analisis $\mathrm{Uji}$ Rangking Bertanda Wilcoxon dengan menggunakan program SPSS. Alasan menggunakan analisis tersebut karena jumlah subjek yang sedikit atau kurang dari 30 (sampel kecil).

\section{Hasil Penelitian}

Sebelum data diolah dengan menggunakan Uji Raking Bertanda Wilcoxon, terlebih dahulu dijabarkan diskripsi data pretest dan posttest beserta 
grafik histogramnya. Data nilai pretest siswa tunanetra sebelum diberikan perlakuan (pretest) diperoleh data nilai sebagai berikut.

Tabel 5.2. Data Nilai Pre Tes

\begin{tabular}{|c|c|}
\hline Nama Siswa & Nilai pre test \\
\hline DN & 43 \\
\hline FD & 54 \\
\hline FM & 61 \\
\hline RK & 55 \\
\hline RD & 50 \\
\hline
\end{tabular}

Data nilai siswa tunanetra sesudah diberikan perlakuan (post test) diperoleh data nilai sebagai berikut.

Tabel 5.3. Data Nilai Post Test

\begin{tabular}{|c|c|}
\hline Nama Siswa & Nilai post test \\
\hline DN & 75 \\
\hline FD & 79 \\
\hline FM & 80 \\
\hline RK & 76 \\
\hline RD & 80 \\
\hline
\end{tabular}

Sumber data : data primer (2016)

Tabel 5.4. Ringkasan Hasil Des Data Nilai Pretes dan Post tes

\begin{tabular}{|c|c|c|c|c|c|c|}
\hline Variabel & N & Variasi & $\begin{array}{c}\text { Nilai } \\
\text { Terendah }\end{array}$ & $\begin{array}{c}\text { Nilai } \\
\text { Tertinggi }\end{array}$ & $\begin{array}{c}\text { Rata- } \\
\text { rata }\end{array}$ & $\begin{array}{c}\text { Std } \\
\text { Deviasi }\end{array}$ \\
\hline Prestasi IPA & 6 & Pretest & 43 & 61 & 52 & 6,65 \\
& 6 & Post test & 75 & 80 & 78 & 2.345 \\
\hline
\end{tabular}

Berdasarkan deskripsi data tersebut diatas, diketahui bahwa rata-rata nilai pada waktu pretest diperoleh nilai 52 dan nilai rata-rata posttest diperoleh nilai. Selisih nilai rata-rata yang cukup banyak memperlihatkan bahwa ada perbedaan antara hasil belajar IPA siswa tunanetra sebelum dan setelah menggunakan modul audio interaktif mengenal akar dan fungsinya. Untuk mengetahui perbedaan itu bermakna secara statistik, akan diuji pada analisis data.

Untuk membuktikan hipotesis bahwa pembelajaran IPA menggunakan modul audio interaktif mengenal bagian akar dan fungsinya efektif untuk siswa tunanetra kelas IV Di SLB YPAB Surabaya, digunakan analisis Uji Rangking Bertanda Wilcoxon, hasil perhitungan SPSS analisis Uji Rangking Bertanda Wilcoxon adalah sebagai berikut.

Tabel 5.6. Hasil Tes Statistik Wilcoxon Signed Ranks Test

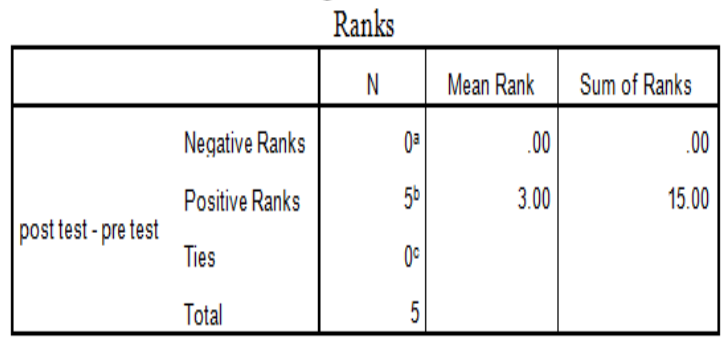

a. post test < pre test

b. post test > pre test c. post test $=$ pre test

Test Statistics $^{a}$

\begin{tabular}{|l|r|}
\hline & post test - pre test \\
\hline$Z$ & $-2.023^{\circ}$ \\
Asymp. Sig. (2-tailed) & .043 \\
\hline
\end{tabular}

a. Wilcoxon Signed Ranks Test

b. Based on negative ranks. 
Hasil uji hipotesis perhitungan nilai pretest dan posttest mengenai pembelajaran IPA menggunakan modul audio interaktif mengenal akar dan fungsinya dihasilkan nilai $\mathrm{Z}$ hitung $=-2.023$ dengan $\mathrm{P}=0.043$ dengan taraf signifikansi $(\alpha) 5 \%$. Sehingga dapat disimpulkan bahwa penggunaan modul audio interaktif mengenal akar dan fungsinya berpengaruh positif terhadap pembelajaran IPA pada siswa tunanetra kelas IV di SLB A YPAB Surabaya.

\section{Pembahasan Hasil Penelitian}

Berdasarkan pembuktian hipotesis di atas, maka dapat disimpulkan bahwa: hasil analisis deskriptif dapat diperoleh nilai ratarata post tes lebih besar 78 dari pada nilai rata-rata pre test 52. Hasil analisis non parametrik diperoleh nilai $\mathrm{Z}=-2.023$ dengan $\mathrm{P}=0.043$, maka hipotesis berbunyi disimpulkan bahwa penggunaan modul audio interaktif mengenal akar dan fungsinya berpengaruh positif terhadap pembelajaran IPA pada siswa tunanetra kelas IV di SLB A YPAB Surabaya diterima kebenarannya.

Penggunaan modul audio interaktif mengenal bagian akar dan fungsinya merupakan salah satu strategi penyampaian pesan kepada siswa tunanetra. Dalam hal ini diharapkan pula dengan menggunakan modul audio interaktif, dapat memudahkan guru menjelaskan materi khususnya konsep pembelajaran IPA khususnya bagian akar dan fungsinya. Banyak manfaat yang diperoleh dari penggunaan modul audio dalam pembelajaran, salah satunya adalah suasana pembelajaran bisa menjadi menyenangkan. Seperti yang dikemukakan oleh Robica (2012) yang menjelaskan bahwa produk media pembelajaran audio dapat memberikan suasana dan lingkungan pembelajaran yang menyenangkan bagi siswa tunanetra sehingga proses penyerapan materi pembelajaran sesuai dengan apa yang diharapkan.

Kemampuan kognitif siswa tunanetra tidak berbeda jauh dengan siswa normal. Sebagaimana dikemukakan oleh Tilman dan Osborn dalam Sunanto (2005) yang menjelaskan bahwa anak tunanetra mendapatkan angka yang hampir sama dengan anak awas, dalam hal berhitung, informasi, dan kosakata, tetapi kurang baik dalam hal pemahaman (comprehention) dan persamaan. Berdasarkan hasil pengamatan yang dilakukan peneliti di lapangan terhadap siswa tunanetra dan wawancara dengan beberapa guru SLB, tingkat kecerdasan siswa tunanetra tidak begitu berbeda dengan siswa normal. Hanya saja siswa tunanetra mempunyai 
kelambatan dalam kejadian visual, pada pelajaran berhitung, informasi, dan kosakata siswa kurang baik dalam hal pemahaman sehingga diperlukan pengulangan.

Keterbatasan indera penglihatan pada siswa tunanetra ini dapat menjadi faktor penghambat dalam pembelajaran, seperti ketika guru memaparkan mengenai benda, warna, dan segala hal yang membutuhkan indera penglihatan. Agar siswa memperoleh pemahaman, maka guru perlu mengulang pembelajaran. Jika guru hanya menggunakan metode ceramah, maka pembelajaran menjadi kurang efektif, karena mereka belum mempunyai pengalaman/pengamatan.

Meskipun guru dapat memaparkan materi tersebut dengan benar, namun proses pembelajaran akan menjadi membosankan dan menyebabkan siswa tunanetra mengantuk.

Lebih lanjut dijelaskan oleh Miarso (2007) bahwa media audio mampu memberikan rangsangan yang bervariasi, mengatasi keterbatasan pengalaman yang dimiliki siswa, media audio memberikan motivasi dan merangsang anak untuk belajar. Hal ini dapat membantu siswa tunanetra dalam pembelajaran IPA khususnya mengenal bagian akar dan fungsinya. Diharapkan pula dengan menggunakan modul audio interaktif mengenal bagian akar dan fungsinya ini, siswa tunanetra tidak lagi tergantung pada guru atau buku materi teks braille yang dirasa kurang aksesibel. Sebagaimana yang disampaikan oleh Ozgur (2007) yang mengemukakan bahwa penggunaan modul audio berdampak positif terhadap pembelajaran karena dapat membantu siswa-siswa tunanetra untuk menyimpan hal-hal yang dipelajari dalam memori jangka panjang, memotivasi siswa untuk belajar dan membantu belajar mandiri.

Penelitian ini hampir sama dengan yang dilakukan oleh Hidayati (2014) yang melakukan pengembangan media audio characteristics of organism song education (chosen) pada pembelajaran IPA biologi terhadap siswa SMPLB-A (tunanetra). Hasil penelitian diperoleh kesimpulan bahwa media audio yang dikembangkan berpengaruh positif terhadap pembelajaran IPA siswa tunanetra. Keenam siswa kelas VII-A dinyatakan tuntas dengan nilai ratarata kelas sebesar 89. Presentase ketuntasan klasikal dari kelas tersebut mencapai $100 \%$. Tanggapan yang diberikan siswa adalah sangat baik dan baik, sedangkan guru menyatakan bahwa media audio yang dikembangkan layak diterapkan pada pembelajaran IPA Biologi siswa tunanetra

Berdasarkan hasil penelitian yang telah dilakukan, terlihat bahwa modul audio 
interaktif mengenal bagian akar dan fungsinya ini dapat meningkatkan pemahaman siswa tunanetra terhadap materi yang disampaikan dan menciptakan lingkungan pembelajaran yang sesuai dengan kebutuhan siswa tunanetra sehingga dapat meningkatkan motivasi belajar siswa. Siswa merasa tertarik dengan modul audio interaktif mengenal bagian akar dan fungsinya karena terdapat unsur interaktifnya dan siswa turut aktif dalam menjawab pertanyaan interaktif yang terdapat dalam modul tersebut.

Dalam penelitian ini terdapat kekurangan karena adanya keterbatasan peneliti mengenai pengetahuan mengenai media audio interaktif. Oleh karena itu dalam menyempurnakan penelitian ini sebaiknya dalam menggunakan media audio yang dapat dimodifikasi sesuai dengan kondisi anak seperti dalam pembelajaran IPA disertai juga dengan media yang bisa diraba. Sehingga informasi yang didapat oleh siswa tidak hanya dari indra pendengaran tapi juga indera peraba. Hal in bisa membantu masuknya infomasi kepada anakk lebih kuat dan tahan lama.

\section{Kesimpulan Dan Saran Kesimpulan}

Dari hasil temuan, didapat hasil uji hipotesis perhitungan nilai pretest dan posttest mengenai pembelajaran IPA menggunakan modul audio interaktif mengenal akar dan fungsinya dihasilkan nilai $\mathrm{Z}$ hitung $=-2.023$ dengan $\mathrm{P}=0.043$ dengan taraf signifikansi $(\alpha)$ 5\%. Sehingga dapat disimpulkan bahwa penggunaan modul audio interaktif mengenal akar dan fungsinya berpengaruh positif terhadap pembelajaran IPA pada siswa tunanetra kelas IV di SLB A YPAB Surabaya.

\section{Saran}

Dalam penelitian ini terdapat kekurangan karena adanya keterbatasan peneliti mengenai pengetahuan mengenai media audio interaktif. Oleh karena itu dalam menyempurnakan penelitian ini sebaiknya dalam menggunakan media audio yang dapat dimodifikasi sesuai dengan kondisi anak seperti dalam pembelajaran IPA disertai juga dengan media yang bisa diraba. Sehingga informasi yang didapat oleh siswa tidak hanya dari indra pendengaran tapi juga indera peraba. Hal in bisa membantu masuknya infomasi kepada anakk lebih kuat dan tahan lama. 


\section{DAFTAR PUSTAKA}

Arikunto, Suharsimi. 2002. Prosedur Penelitian. Jakarta: PT. Rineka Cipta

Asyhar, Rayandra. 2012. Kreatif Mengembangkan Media Pembelajaran. Jakarta: Referensi Jakarta

Baraga, N. 1986. Foundations of Education for Blind and Visually Handicapped Children and Youth: Theory and Practice, American Foundation For Blind, Inc,. New York

Hamdani. 2011. Strategi Belajar Mengajar. Bandung: Pustaka Setia

Hatip, Ahmad. 2008. Proses berpikir siswa SMP dalam menyelesaikan soal-soal faktorisasi suku aljabar ditinjau dari perbedaan kemampuan matematika dan perbedaan gender. Tesis pascasarjana Unesa

Hayati, Kulsum Nur. 2012. Model Ujian Nasional Berbasis Audio untuk Siswa Tunanetra. Penelitian dipresentasikan dalam Konferensi Ilmiah Nasional "Asesmen dan Pembangunan Karakter Bangsa" HEPI UNESA 2012

Hidayati, Fidya. 2014. Pengembangan Media Audio Characteristics of Organism Song Education (Chosen) Pada Pembelajaran IPA Biologi Di SMPLB-A (Tunanetra) . Unnes Journal of Biology Education 3 (2) (2014) 156-163

Miarso, Yusufhadi. (2007). Menyemai Benih Teknologi Pendidikan. Jakarta: Kencana

Pertuni (2004). Anggaran Rumah Tangga Persatuan Tunanetra Indonesia. Jakarta: Pertuni.
Ozgur, Aydin Ziya. 2007. Evaluating Audio Books as Supported Course Materials In Distance Education: The Experiences of The Blind Learners. Anadolu University, open education faculty. The Turkish online journal of educational technology - tojet October 2007 ISSN: 1303-6521 volume 6 issue 4 article 2

Prastowo, Andi. 2012. Panduan Kreatif Membuat Bahan Ajar Inovatif. Jogjakarta: DIVA Press

Riyana, Cepi. 2007. Pedoman Pengembangan Modul Multimedia Interaktif. Bandung: Program P3AI Universitas Pendidikan Indonesia

Robica. 2012. Tesis. Pengembangan Media Pembelajaran Audio Dalam Meningkatkan Kemampuan Menyimal Pada Mata Pelajaran Bahasa Inggris Siswa Sekolah Dasar. Surabaya: Universitas Negeri Surabaya

Sondang P. Siagian, 2001. Pengertian Efektivitas Pembelajaran. Online. http://othenk.blogspot.id/2008/11/pe ngertian-tentang-efektivitas.html (diakses 20 Juni 2015).

Sukiman. 2012. Pengembangan Media Pembelajaran. Pedagogia. Yogyakarta

Sunanto, Djuang. 2005. Potensi Anak Berkelainan Penglihatan. Departemen pendidikan Nasional

Suryabrata, Sumadi. 2004. Metodologi Penelitian. Jakarta : PT. Raja Grafindo Persada

Undang-Undang Sistem Pendidikan Nasional (UUSPN) No. 20 Tahun 2003

Widdjajatin, A. dan Hetipeew. 1996. Ortopedagogik Tunanetra 1. Jakarta: 
Departemen Pendidikan dan Kebudayaan

Willis, D. H. (1979). Relationship between Visual Acuity, Reading Mode, and Scool Systems for the Blind Children. Exceptional Children, 46, 3, 186-191

Wena, Made. 2008. Strategi Pembelajaran Inovatif Kontemporer. JakartaTimur: Bumi Aksara 